\title{
Vanadium-based polyoxometalate as new material for sodium ion battery anodes
}

Steffen Hartung ${ }^{1,2 \#}$, Nicolas Bucher ${ }^{1,2 \#}$, Han-Yi Chen ${ }^{1,3}$, Rami Al-Oweini, Sivaramapanicker Sreejith ${ }^{6}$, Parijat Borah ${ }^{6}$, Zhao Yanli ${ }^{6}$, Ulrich Kortz ${ }^{4}$, Ulrich Stimming ${ }^{1,2}$, Harry E. Hoster ${ }^{1,2,5}$, Madhavi Srinivasan ${ }^{1,3,5 *}$

*E-mail: Madhavi@ntu.edu.sg

${ }^{1}$ TUM CREATE, 1 CREATE Way, \#10-02 CREATE Tower, Singapore

${ }^{2}$ Technische Universität München, 85748 Garching, Germany

${ }^{3}$ School of Materials Science and Engineering, Nanyang Technological University,

Singapore 639798, Singapore

${ }^{4}$ School of Engineering and Science, Jacobs University, P.O. Box 750561, 28725

Bremen, Germany

${ }^{5}$ Energy Research Institute @ NTU (ERI@N) Research Techno Plaza, 50 Nanyang Drive, Singapore 637553

${ }^{6}$ Division of Chemistry and Biological Chemistry, School of Physical and Mathematical Sciences, Nanyang Technological University, 21 Nanyang Link, 637371, Singapore

\# Steffen Hartung and Nicolas Bucher contributed equally to this manuscript. 


\section{Abstract}

Affordable energy storage is crucial for a variety of technologies. One option is sodium ion batteries (NIBs) for which, however, suitable anode materials are still a problem. We report on the application of a promising new class of materials, polyoxometallates (POMs), as an anode in NIBs. Specifically $\mathrm{Na}_{6}\left[\mathrm{~V}_{10} \mathrm{O}_{28}\right] \cdot 16 \mathrm{H}_{2} \mathrm{O}$ has been synthesized and characterized. Galvanostatic tests revealed a reversible capacity of approximately $276 \mathrm{~mA} \mathrm{~h} \mathrm{~g}^{-1}$ with an average discharge potential of $0.4 \mathrm{~V}$, as well as a high cycling stability. The underlying mechanism was rationalized to be an insertion of $\mathrm{Na}^{+}$in between the $\left[\mathrm{V}_{10} \mathrm{O}_{28}\right]^{6-}$. anions rather than an intercalation into a crystal structure; the accompanying reduction of $V^{+V}$ to $V^{+I V}$ was confirmed by X-Ray Photoelectron Spectroscopy. Finally, a working full-cell set-up is presented with the POM as the anode, substantiating the claim that $\mathrm{Na}_{6}\left[\mathrm{~V}_{10} \mathrm{O}_{28}\right] \cdot 16 \mathrm{H}_{2} \mathrm{O}$ is a promising option for future high-performing sodium ion batteries. 


\section{Introduction}

In recent years, research in the field of electrochemical energy storage has intensified as the need to reliably and economically store electricity has been identified as a crucial factor in a broad variety of fields. This includes portable electronic devices and electrically powered vehicles, which require high power and energy densities. Another area where energy storage will play a key role is the stabilization of the electricity grid. As green ways to harvest electricity from renewable sources like wind or solar power become increasingly popular, economical solutions to smoothen electricity peaks are paramount for these green technologies to play a major role in the energy mix. However, for such large-scale applications the crucial factor is neither energy nor power density, but rather cost. Thus, novel battery technologies that reduce the storage cost are being researched. One promising candidate is sodium ion batteries, due to the relative abundance of sodium in the earth's crust and, consequently, its lower cost. ${ }^{1-3}$ Furthermore, in sodium ion batteries copper, current collectors can be replaced with the cheaper aluminium as sodium, as opposed to lithium, does not alloy with aluminium. ${ }^{4-6}$ However, for sodium ion batteries to become a viable alternative to lithium ion batteries, novel materials need to be developed that can compete with regard to capacity and cycle behaviour. For cathode materials, layered oxides seem to be the material of choice, with a variety of sodium metal oxides (metal: manganese, cobalt, vanadium, iron) being researched, including different compositions / doping of various metals. ${ }^{6-10}$ So far, anode materials seem to be a big challenge, as graphite anodes commercially employed in lithium ion batteries are unsuitable for sodium ion batteries owing to the graphite interlayer spacing that is not sufficient to intercalate sodium ions. ${ }^{11}$ Thus, several prospective anode materials are being researched 
which fulfil the requirements for commercial applications of sodium ion batteries ${ }^{12}, a$ selection of which is presented in Figure 1. Research focuses on different storage mechanisms for $\mathrm{Na}^{+}$-ions in the active material. Recent works on intercalation materials include amorphous $\mathrm{TiO}_{2}{ }^{13}$, and layered $\mathrm{P} 2-\mathrm{Na}_{0.66}\left[\mathrm{Li}_{0.22} \mathrm{Ti}_{0.78}\right] \mathrm{O}_{2}{ }^{14}$. The first forms $\mathrm{Na}_{x} \mathrm{TiO}_{2}$ in-situ with an approximate capacity of $140 \mathrm{~mA} \mathrm{~h} \mathrm{~g}{ }^{-1}$ at potentials between 0.9 and $2.0 \mathrm{~V}$, while the latter provides $130 \mathrm{mAh} \mathrm{g}^{-1}(\mathrm{C} / 10)$ between $0.4-$ 1.25 V. Phase change materials are mainly metal oxides; titanium-based materials seem promising with capacities of approximately $200 \mathrm{~mA} \mathrm{~h} \mathrm{~g}^{-1}$ for $\mathrm{Na}_{2} \mathrm{Ti}_{3} \mathrm{O}_{7}{ }^{15}$; however, only five cycles are shown. Balaya et. al. reported $180 \mathrm{~mA} \mathrm{~h} \mathrm{~g}^{-1}$ for this material, with $120 \mathrm{~mA} \mathrm{~h} \mathrm{~g}^{-1}$ after 50 cycles. ${ }^{16} \mathrm{Li}_{4} \mathrm{Ti}_{5} \mathrm{O}_{12}$ was found to provide $155 \mathrm{~mA}$ $\mathrm{h} \mathrm{g}^{-1}$ at an average potential of $0.75 \mathrm{~V} .{ }^{17}$ Furthermore, phosphate-based NASICON materials have also been explored recently. ${ }^{18}$ Metal-based anodes react with $\mathrm{Na}^{+}$ions by forming alloys; often, a carbon matrix is added to alleviate volume changes. Oh et. al., for example, described the application of tin-carbon in a sodium ion full ce $\|^{19}$. Although alloy materials are considered to be safe anodes with a high capacity, cycle stability is usually poor, due to the large volume changes during (de)insertion, which is often alleviated by introducing a carbon matrix. ${ }^{20,21}$ Qian et. al. showed that $\mathrm{Sb} / \mathrm{C}$ composites can deliver around $600 \mathrm{~mA} \mathrm{~h} \mathrm{~g}^{-1}\left(100 \mathrm{~mA} \mathrm{~g}^{-1}\right) \cdot{ }^{22}$ Work in the field of carbon-based materials focuses on hard-carbon, which consists of partially graphitized areas and irregular regions forming cavities. Stevens et. al. found that, for graphitic regions, an intercalation mechanism takes place up to a capacity of around $100 \mathrm{~mA} \mathrm{~h} \mathrm{~g}^{-1}$, followed by an insertion of $\mathrm{Na}^{+}$in the cavities, which contributes additional $150 \mathrm{~mA} \mathrm{~h} \mathrm{~g}^{-1}$ (C/10). ${ }^{23}$ While hard-carbons combine reasonable capacities with high stabilities, safety problems arise due to the low insertion voltage which facilitates Na-plating. Another class of materials that has 
received some attention recently is organic materials. Zhao et. al. and Park et. al., for example, recently reported 225 and $300 \mathrm{~mA} \mathrm{~h} \mathrm{~g}{ }^{-1}$, respectively, for $\mathrm{Na}_{2} \mathrm{C}_{8} \mathrm{H}_{4} \mathrm{O}_{4}$ at 0.4 $\mathrm{V}^{24,25}$; here, disodium terephthalate reacts to tetrasodium terephthalate through a radical intermediate.

Polyoxometalates (POM) are anionic metal-oxo clusters of early transition metal ions in high oxidation states and they exhibit unique structural and compositional properties leading to potential applications in various areas such as catalysis, magnetism, electro- and photochemistry, as well as in materials science ${ }^{26-31}$. It has been shown that POMs can also be used as electrode material in lithium ion batteries and that their multi-electron redox properties could provide a good capacity for lithium-based systems, especially for the Keggin-based POM structures ${ }^{32-37}$. A unique characteristic of POMs as electrode material in batteries is that they do not consist of extended crystal structures, but rather of isolated, discrete polyanions, making them an intermediate between intercalation electrodes and organic radical electrodes $^{32,34,36}$. Thus, POMs tap into the same advantageous mechanism like sodium terephthalate and hard-carbons, i.e., $\mathrm{Na}^{+}$-insertion in intercluster cavities. Therefore, strain on crystal structures and resulting structural deterioration can be excluded as potential reasons for capacity fading. Moreover, safety features can be enhanced when this insertion occurs at a higher potential than the one at which Naplating occurs.

Even though polyoxometalates have been tested for lithium ion batteries, no reports of polyoxometalate-based electrodes for sodium ion batteries have been published. In this work, we report on the properties of the decavanadate ion in $\mathrm{Na}_{6}\left[\mathrm{~V}_{10} \mathrm{O}_{28}\right] \cdot 16 \mathrm{H}_{2} \mathrm{O}$ POM, and show its suitability as anode in sodium ion batteries. 
We first describe its structural properties, and then discuss the electrochemical data, including cyclic voltammetry and charge / discharge performance.

\section{Results and Discussion}

Material characterization of $\mathrm{Na}_{6}\left[\mathrm{~V}_{10} \mathrm{O}_{28}\right] \cdot 16 \mathrm{H}_{2} \mathrm{O} .{ }^{51} \mathrm{~V}-\mathrm{NMR}$ measurements revealed the characteristic signals of the decavanadate, $\left[\mathrm{V}_{10} \mathrm{O}_{28}\right]^{6-}(-514,-500$ and -424 ppm), indicating the successful synthesis of the targeted structure (Fig. $2 a)^{38,39}$. This was confirmed by the FTIR spectrum, which showed the typical absorption bands of $\left[\mathrm{V}_{10} \mathrm{O}_{28}\right]^{6-}$, with asym. stretching at 847 and 746 , and symmetric stretching at 521 $\mathrm{cm}^{-1}$ being attributable to the $\mathrm{V}-\mathrm{O}-\mathrm{V}$ bridging, while the mode at $956 \mathrm{~cm}^{-1}$ is attributed to the terminal $\mathrm{V}=\mathrm{O}_{\text {stretch }}$ bond (Fig. $\left.2 \mathrm{~b}\right)^{40,41}$. Inductively coupled plasma analysis revealed $\mathrm{Na}-\mathrm{V}$ ratio of 0.59 , confirming the expected stoichiometry within the POM.

TGA of the POM shows a weight loss starting already at temperatures slightly above room temperature, which continues until $220^{\circ} \mathrm{C}$ (Fig. 2c). The total weight loss of $21 \%$ is consistent with the removal of 16 water molecules from the structure, indicating the presence of 16 molecules of crystal water per formula unit. Thus, the overall chemical formula is $\mathrm{Na}_{6}\left[\mathrm{~V}_{10} \mathrm{O}_{28}\right] \cdot 16 \mathrm{H}_{2} \mathrm{O}$. As the coated electrode were dried at $110^{\circ} \mathrm{C}$ under vacuum for several hours, it can safely be assumed that no crystal water is present after the drying process, and the chemical composition of the POM on the electrode is hence $\mathrm{Na}_{6}\left[\mathrm{~V}_{10} \mathrm{O}_{28}\right]$.

Surface area of the material, as measured by BET, was $21 \mathrm{~m}^{2} \mathrm{~g}^{-1}$; the corresponding adsorption-desorption isotherms can be seen in Figure 3a. Pore-size distribution, as elucidated by $\mathrm{BJH}$, ranges from $\sim 3$ - $5 \mathrm{~nm}$, indicating mesoporosity, 
for the majority of pores; for the remainder, pore size varies between $\sim 5-160 \mathrm{~nm}$ (Fig. 3b).

According to FESEM and HRTEM measurements (Fig. 4), the $\mathrm{Na}_{6}\left[\mathrm{~V}_{10} \mathrm{O}_{28}\right] \cdot 16 \mathrm{H}_{2} \mathrm{O}$ POM shows a rod-like morphology in the solid state; the micro-rods have a diameter of $0.5-1 \mu \mathrm{m}$ and a typical length of several micrometers, resulting in a typical aspect ratio of 5-10. According to TEM, the POM microrods are polycrystalline, and show a random orientation with d-spacings of 0.769 and $0.333 \mathrm{~nm}$. These findings are consistent with the ICSD data file 66807. As discussed above, one characteristic of discrete POMs is that they do not consist of extended crystal structures, but rather consist of individual, well-separated polyanions. In the case of decavanadate examined in this work, the clusters consist of $\left[\mathrm{V}_{10} \mathrm{O}_{28}\right]^{6-}$ units, comprising ten edgeshared $\mathrm{VO}_{6}$ octahedra. As discussed in previous publications about the lithium salt, $\mathrm{Li}_{6}\left[\mathrm{~V}_{10} \mathrm{O}_{28}\right]$, crystal water molecules and counter cations separate the individual $\left[\mathrm{V}_{10} \mathrm{O}_{28}\right]^{6-}$ ions. Upon heating, the crystal water can be removed so that the material consists of individual $\left[\mathrm{V}_{10} \mathrm{O}_{28}\right]^{6-}$ clusters separated only by the alkali ions. As the same $\left[\mathrm{V}_{10} \mathrm{O}_{28}\right]^{6-}$ units make up the structure of $\mathrm{Na}_{6}\left[\mathrm{~V}_{10} \mathrm{O}_{28}\right] \cdot 16 \mathrm{H}_{2} \mathrm{O}$, and TGA shows that crystal water molecules can be removed from the structure, the same overall behavior is assumed. The lattice would then consist only of sodium ions separating the individual $\left[\mathrm{V}_{10} \mathrm{O}_{28}\right]^{6-}$ clusters. Thus, sodium is not incorporated into the crystal structure of the $\left[\mathrm{V}_{10} \mathrm{O}_{28}\right]^{6-}$ clusters, but rather inserted into the space between different clusters.

Electrochemical measurements. In the cyclic voltammogram the half-cell is first discharged, and subsequently cycled between $0.01 \mathrm{~V}$ and $3 \mathrm{~V}$. In the first discharge, i.e., in the first process of inserting $\mathrm{Na}^{+}$ions into the POM structure, various distinct 
reduction peaks can be seen at 2.8, 2.2, 1.1, and $0.2 \mathrm{~V}$ in Figure 5a. This indicates distinct reduction or ordering processes. However, as the corresponding oxidation peaks are, if existent, significantly less pronounced, these processes are irreversible. In the subsequent cycles, no distinct peaks are occurring and the electrochemical processes do not occur at specific voltages. Hence, the cyclic voltammogram resembles that of a supercapacitor rather than that of a typical intercalation process for the major part of the voltage range. However, two minor peaks become visible at a potential of $0.01 \mathrm{~V}$ for the reduction and 0.09 for the oxidation, indicating a defined electrochemical process. This can potentially be attributed to the acetylene black in the electrode.

The capacitive behavior can be explained by the special structural and morphological characteristics of POMs discussed previously. It has been shown before for lithium ion batteries that POMs do not act as an intercalation material. In fact, the ions move between the polyanionic clusters and seem to be adsorbed at the surface. ${ }^{35,36}$ Thus, the capacitive process for $\mathrm{Na}_{6}\left[\mathrm{~V}_{10} \mathrm{O}_{28}\right]$ is based on a continuous insertion of $\mathrm{Na}^{+}$-ions into the cavities between the $\left[\mathrm{V}_{10} \mathrm{O}_{28}\right]^{6-}$ clusters. X-Ray Photoelectron Spectroscopy was employed to examine whether the behavior is only physical adsorption, or accompanied by electrochemical redox reactions. As Figure 6 indicates, in the pristine POM material only vanadium with an oxidation state of $+\mathrm{V}$ is present. When discharged, however, vanadium with an oxidation state of +IV can be observed as well. Thus, it can be said that $\mathrm{Na}^{+}$-ions are not physically adsorbed on the surface of the $\left[\mathrm{V}_{10} \mathrm{O}_{28}\right]^{6-}$ clusters, but a reduction from $V^{+V}$ to $V^{+I V}$ is induced. Therefore, these clusters seem to act as redox centers in the sense that $\mathrm{Na}^{+}$-ions are taken up between them while vanadium ions are reduced to maintain the charge balance. 
The hypothesis of a continuous insertion of $\mathrm{Na}^{+}$-ions is substantiated by the charge I discharge profile, in which the lack of plateaux indicates a steady insertion of $\mathrm{Na}^{+}$ (Fig. 5b). Unlike phase change materials, in which $\mathrm{Na}^{+}$continuously occupies a defined lattice space and thus triggers a structural change at a specified voltage, POMs do not exhibit these defined insertion processes at a distinct voltage. This variety of insertion sites results in a variety of chemical potentials of the $\mathrm{Na}^{+}$-ions in the material, which in turn results in a virtually continuous distribution of insertion voltages.$^{23}$ This would explain the absence of peaks in the CV and the slopy charge / discharge curves, rather than a distinct plateau. In previous works, similar-looking curves for LIBs have been fitted using the Redlich-Kister relation. ${ }^{42,43}$ However, as we do not yet have a full understanding of the $\mathrm{Na}^{+}$-insertion mechanism into our POM and have doubts if the theoretical background of the Redlich-Kister (thermodynamic of solutions ${ }^{42}$ ) derivation justify its application in this case, we refrain from performing this fit. The average discharge potential, as measured by the potential at which the area under the $10^{\text {th }}$ discharge curve was cut in half, was found to be $0.4 \mathrm{~V}$.

In the first discharge cycles, the capacities exceed $300 \mathrm{~mA} \mathrm{~h} \mathrm{~g}^{-1}$; these high values are not achieved in subsequent cycles and can probably be attributed to the formation of a solid-electrolyte interphase, based on the partial decomposition of electrolyte. This is a known phenomenon and is also substantiated by the charges transferred during cyclic voltammetry as found by integration. While for the first cycle the charge transferred during reduction is approximately $150 \%$ of the charge transferred during reduction, this number decreases for subsequent cycles. For the following cycles, discharge capacities stabilize and for the tenth cycle reach approximately $276 \mathrm{~mA} \mathrm{~h} \mathrm{~g}^{-1}$ for a current rate of $20 \mathrm{~mA} \mathrm{~g}^{-1}$. As the rate test in Figure 
5c shows, discharge capacities decrease for higher current rates, giving $221 \mathrm{~mA} \mathrm{~h} \mathrm{~g}$ ${ }^{1}$ for $50 \mathrm{~mA} \mathrm{~g}^{-1}$ (cycle 15), $173 \mathrm{~mA} \mathrm{~h} \mathrm{~g}^{-1}$ for $100 \mathrm{~mA} \mathrm{~g}^{-1}$ (cycle 20) and $97 \mathrm{~mA} \mathrm{~h} \mathrm{~g}^{-1}$ for $200 \mathrm{~mA} \mathrm{~g}^{-1}$ (cycle 25). When changing the current rate again back to $50 \mathrm{~mA} \mathrm{~g}^{-1}$, discharge capacity is rather stable on a high level, with $220 \mathrm{~mA} \mathrm{~h} \mathrm{~g}^{-1}$ for cycle 27 , compared to $221 \mathrm{~mA} \mathrm{~h} \mathrm{~g}^{-1}$ for cycle 15 . This indicates that the fading, even though capacities are lower at higher current rates, is not exacerbated when increasing the currents. The reason for this remarkable cycle stability is probably the unique structural and morphological features of POMs. As the $\mathrm{Na}^{+}$-ions (de-)insert into / from cavities between the $\left[\mathrm{V}_{10} \mathrm{O}_{28}\right]^{6-}$ clusters and are not built into a defined crystal lattice, structural strain is minimized. Consequently, a major cause for capacity fading is omitted, and stability is increased. The observable capacity fading is possibly due to electrolyte decomposition; as reported in the literature, this can be remedied by adding fluorinated ethylene carbonate to the electrolyte. ${ }^{5}$ Tests to examine the effect of this additive to the POM system are under way.

The achieved capacities are in the same regions as the values reported for hard carbon (Fig. 1). However, as the insertion process takes place at higher voltages, the risk of Na-plating is eliminated, which leads to an increase in safety. When compared to phase-change materials like $\mathrm{Li}_{4} \mathrm{Ti}_{5} \mathrm{O}_{12}$ and $\mathrm{Na}_{2} \mathrm{Ti}_{3} \mathrm{O}_{7}, \mathrm{Na}_{6}\left[\mathrm{~V}_{10} \mathrm{O}_{28}\right]$ reaches higher capacities in a voltage region that lies between the two aforementioned materials. The same classification can be made for intercalation materials, i.e., the POM lies between $\mathrm{TiO}_{2}{ }^{13}$ and $\mathrm{P} 2-\mathrm{Na}_{0.66}\left[\mathrm{Li}_{0.22} \mathrm{Ti}_{0.78}\right] \mathrm{O}_{2}{ }^{14}$ with respect to voltage, and exceeds both materials regarding capacity. Alloy materials exceed $\mathrm{Na}_{6}\left[\mathrm{~V}_{10} \mathrm{O}_{28}\right]$ with regard to capacity; however, they typically have the disadvantage of low cycle stabilities. Even though this can be improved by embedding the active material into a matrix (e.g., carbon nanotubes), this often requires complex synthesis methods, which is a barrier 
to commercial applications. Sodium terephthalates ${ }^{24,25}$ match and exceed $\mathrm{Na}_{6}\left[\mathrm{~V}_{10} \mathrm{O}_{28}\right]$ with regard to capacities, while their plateau during discharge matches the average discharge voltage of the POM.

As discussed above, the chemical formula of the electrode material can be assumed to be $\mathrm{Na}_{6}\left[\mathrm{~V}_{10} \mathrm{O}_{28}\right]$. With respect to this composition, the capacity of $1 \mathrm{Na}^{+}$ ion is $24.5 \mathrm{~mA} \mathrm{~h} \mathrm{~g}{ }^{-1}$. Reduction of all vanadium $+\mathrm{V}$ to $+\mathrm{IV}$ would be accompanied by an insertion of $10 \mathrm{Na}+-$ ions per formula unit $\mathrm{Na}_{6}\left[\mathrm{~V}_{10} \mathrm{O}_{28}\right]$, i.e., of $245 \mathrm{~mA} \mathrm{~h} \mathrm{~g}{ }^{-1}$. As discussed, in the first discharge cycles the current occurring with the formation of a SEI adds to the reversible capacity of the insertion of sodium ions, which expresses itself as a rather high fading during the initial cycles. Furthermore, this is also substantiated by a coulomb efficiency of $>100 \%$ in the first cycles. This would explain that, in case $10 \mathrm{Na}^{+}$are inserted, the measured capacity exceeds theoretical capacity in the beginning. Another potential reason could be minor electrochemical activity of the acetylene black in the electrode. When increasing the current rate to $50 \mathrm{~mA} \mathrm{~g}^{-1}$, discharge capacities drop to values around $221 \mathrm{~mA} \mathrm{~h} \mathrm{~g}^{-1}$. The insertion of $\mathrm{Na}^{+}$would have to be accompanied by a reduction of $V^{+V}$ to $V^{+I V}$. According to XPS measurements, as discussed before, this reduction indeed takes place. However, $V^{+V}$ is still present in the discharged sample. This can either be attributed to an incomplete reduction of vanadium or to a re-oxidation during ex-situ sample handling. As the measured discharged sample was briefly exposed to air during the measurement, the oxygen in the air might have re-oxidized some from $V^{+I V}$ to $V^{+V}$. However, based on the achieved capacity we assumed, from a mechanistic point of view, that ten additional $\mathrm{Na}^{+}$-ions are inserted per cluster, resulting in the following reaction:

$$
N a_{6}\left[V_{10}^{+V} O_{28}\right]+10 N a^{+}+10 e^{-} \rightarrow N a_{16}\left[V_{10}^{+I V} O_{28}\right]
$$


As an additional substantiation to the hypothesis of reversible redox reactions, a sodium full cell with $\mathrm{Na}_{6}\left[\mathrm{~V}_{10} \mathrm{O}_{28}\right]$ as anode and spherical sodium manganese oxide ${ }^{44}$ as cathode was built. It is important to note that for this full cell the target was not to optimize performance, but rather to conduct a proof-of-concept that $\mathrm{Na}_{6}\left[\mathrm{~V}_{10} \mathrm{O}_{28}\right]$ can be used for full-cells and undergoes reversible redox reactions. As can be seen in the cyclic voltammogram in Figure $5 \mathrm{a}$, this is the case. The system exhibits several reversible electrochemical processes, even though at this point the variety of peaks cannot be attributed to defined electrochemical processes, as the resulting $\mathrm{CV}$ is a superposition of anodic and cathodic reactions as well as complex sodium ordering processes. However, the peaks clearly indicate reversible redox processes, which substantiate the assumption that the POM undergoes electrochemical reactions. Moreover, as batteries with metallic sodium electrodes pose significant safety risks, full cells without metallic sodium are essential for application-based problems. With this full-cell set-up demonstrated here, a capacity of $140 \mathrm{~mA} \mathrm{~h} \mathrm{~g}^{-1}$ (with regard to the mass of $\mathrm{Na}_{6}\left[\mathrm{~V}_{10} \mathrm{O}_{28}\right]$ ) was achieved for a voltage range of $0.1-4.0 \mathrm{~V}$. As the sodium manganese oxide was the limiting factor in this set-up, a higher mass of this material had to be used, so that the capacity with regard to the mass of NMO, would be inherently lower (as it would obviously be for the total mass of active material, i.e., anode + cathode, in the cell). However, this shows that $\mathrm{Na}_{6}\left[\mathrm{~V}_{10} \mathrm{O}_{28}\right] \cdot 16 \mathrm{H}_{2} \mathrm{O}$ not only shows promising half-cell data, but is also an interesting option for sodium ion full cells.

\section{Conclusion}

We have introduced POMs as a new class of materials for sodium ion batteries and demonstrated their capability as anode material with good cycle stability. 
$\mathrm{Na}_{6}\left[\mathrm{~V}_{10} \mathrm{O}_{28}\right] \cdot 16 \mathrm{H}_{2} \mathrm{O}$ was synthesized via a known procedure and characterized by ${ }^{51}$ V-NMR and FTIR. Cyclic voltammetry and charge / discharge profiles showed no distinct peaks or plateaux respectively, but continuous slopes. This can be attributed to the insertion of $\mathrm{Na}^{+}$-ions between the $\left[\mathrm{V}_{10} \mathrm{O}_{28}\right]^{6-}$ anions instead of into defined crystal interstices. We suggest that this working principle of vanadium POM electrodes is also responsible for the good cycle stability and the negligible "damage" caused by cycling at higher current rates. Finally, we demonstrated that vanadium POM electrodes function as anodes in sodium ion full cells, using sodium manganese oxide as cathode material. 


\section{Methods}

Synthesis. Sodium decavanadate, $\mathrm{Na}_{6}\left[\mathrm{~V}_{10} \mathrm{O}_{28}\right] \cdot 16 \mathrm{H}_{2} \mathrm{O}$, was synthesized according to Domaille et. al. ${ }^{38}$. Typically, $3 \mathrm{~g}$ of $\mathrm{NaVO}_{3}$ is dissolved in de-ionized water (100 $\mathrm{mL}$ ); then, $4 \mathrm{M} \mathrm{HCl}$ is added to acidify the solution until a $\mathrm{pH}$ of 4.8 is reached. The solution is filtered and addidtional $\mathrm{HCl}$ is added to maintain a $\mathrm{pH}$ of around 4.5. Subsequently, ethanol $(95 \%, 200 \mathrm{~mL})$ was added to precipitate $\mathrm{Na}_{6}\left[\mathrm{~V}_{10} \mathrm{O}_{28}\right] \cdot 16 \mathrm{H}_{2} \mathrm{O}$ as an orange bulk product, which is then filtrated and air-dried.

Characterization. The product was characterized by Vanadium Nuclear Magnetic Resonance spectroscopy ( ${ }^{51} \mathrm{~V}$ NMR) and Fourier Transform Infrared Spectroscopy (FTIR). NMR measurements were performed on a 400-MHz JEOL-ECX instrument in $5 \mathrm{~mm}$ tubes at $105.4 \mathrm{MHz}$. FTIR was measured with a PerkinElmer Frontier FT-IR Spectrometer using $\mathrm{KBr}$ pellets. For inductively coupled plasma spectroscopy (ICP) measurements, a Dual-view Optima 5300 DV ICP-OES system was used. Field Emission Scanning Electron Microscopy (FESEM, JEOL JSM 7600F) and High Resolution Transmission Electron Microscopy (HRTEM, JOEL-JSM 2100F) were used to elucidate information on the morphology of $\mathrm{Na}_{6}\left[\mathrm{~V}_{10} \mathrm{O}_{28}\right] \cdot 16 \mathrm{H}_{2} \mathrm{O}$. $\mathrm{N}_{2}$ adsorption-desorption isotherms were used to determine the Brunau-EmmetTeller (BET) surface area and Barrett-Joyner-Halenda $(\mathrm{BJH})$ pore size distribution. Thermogravimetric Analysis (TGA) was performed on a TA Instruments SDT Q600 thermobalance to test the thermal stability of the product. The flow rate of nitrogen was $100 \mathrm{~mL} \mathrm{~min}{ }^{-1}$, and the temperature range was 20 to $800{ }^{\circ} \mathrm{C}$ with a heating rate of $5^{\circ} \mathrm{C} \min ^{-1}$. 
Electrochemistry. The composite electrodes were prepared by mixing the POM with acetylene black (Alfa Aesar, > 99\%) and polyvinylidene fluoride (PVDF, Arkema, Kynar HSV 900) binder in the weight ratio 60:20:20 with N-Methyl-2-pyrrolidone (NMP) to form a homogeneous slurry. This mixture was coated on an Al foil using a doctor blade; the coating was dried in air at $80^{\circ} \mathrm{C}$ to remove the NMP. The coating was punched into pieces with a diameter of $16 \mathrm{~mm}$, which were then roll-pressed. Subsequently, they were dried at $110^{\circ} \mathrm{C}$ under vacuum. These electrodes were then assembled in 2016 coin cells with circular metallic sodium pieces with a diameter of $16 \mathrm{~mm}$ as the anode, and glass fibre (Whatman) as the separator. A $1 \mathrm{M}$ solution of $\mathrm{NaClO}_{4}$ (Sigma Aldrich, $\geq 98 \%$ ) in a mixture of ethylene carbonate and propylene carbonate (1:1 weight \%, EC: $99 \%$, PC: Sigma Aldrich, $\geq 99.7 \%)$ was employed as electrolyte. Cyclic voltammetry was measured using a BioLogic potentiostat, and a Neware battery tester was used for galvanostatic charge / discharge tests. 


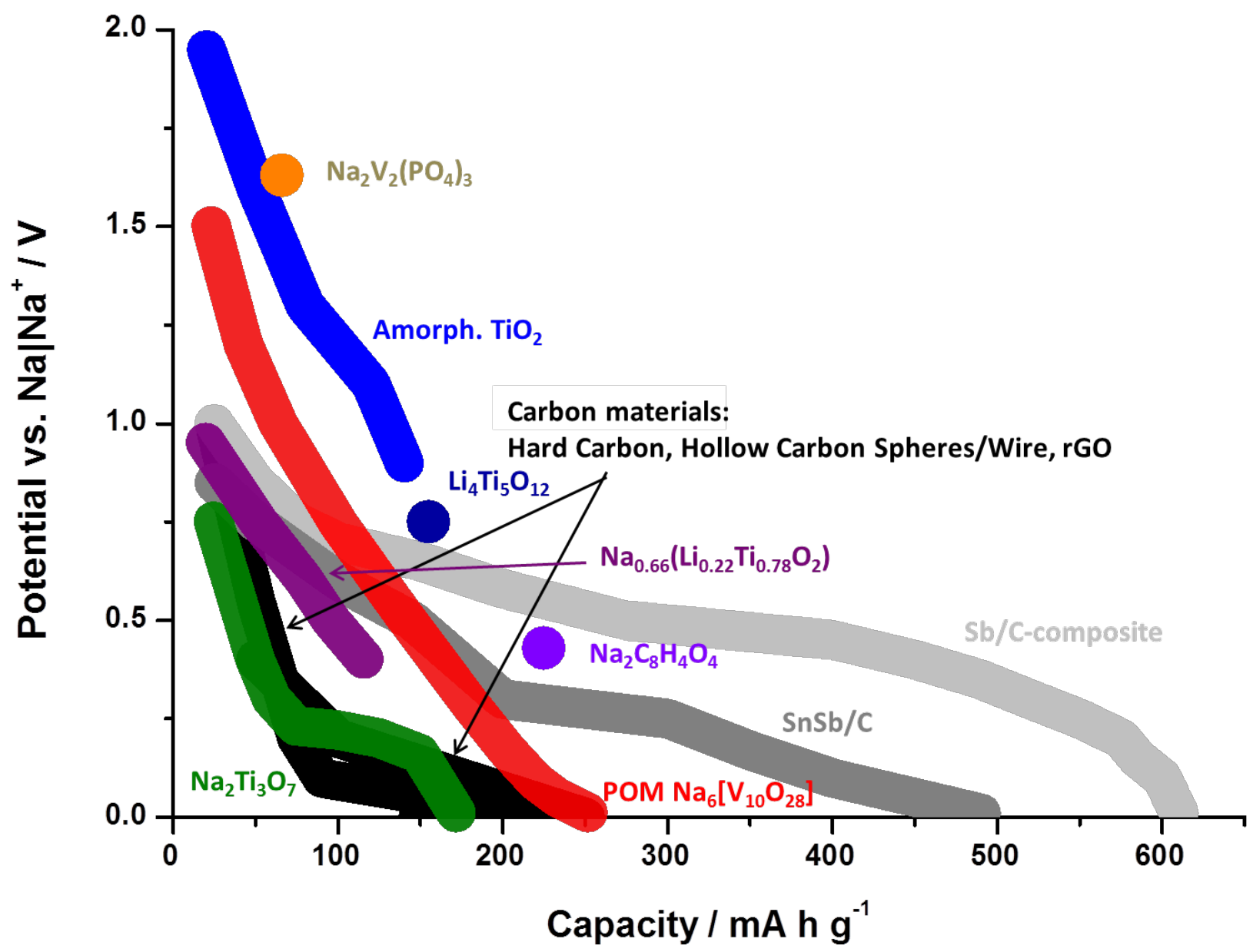

Figure 1 | Overview of different anode materials for sodium ion batteries.

Illustrates the voltage profiles of different sodium ion battery anode materials. The circles represent potentials at which the respective materials have a plateau; for the other materials, the voltage profile is indicated. The capacities shown here represent approximate values after initial stabilization, i.e., after irreversible reactions in the first cycles. 

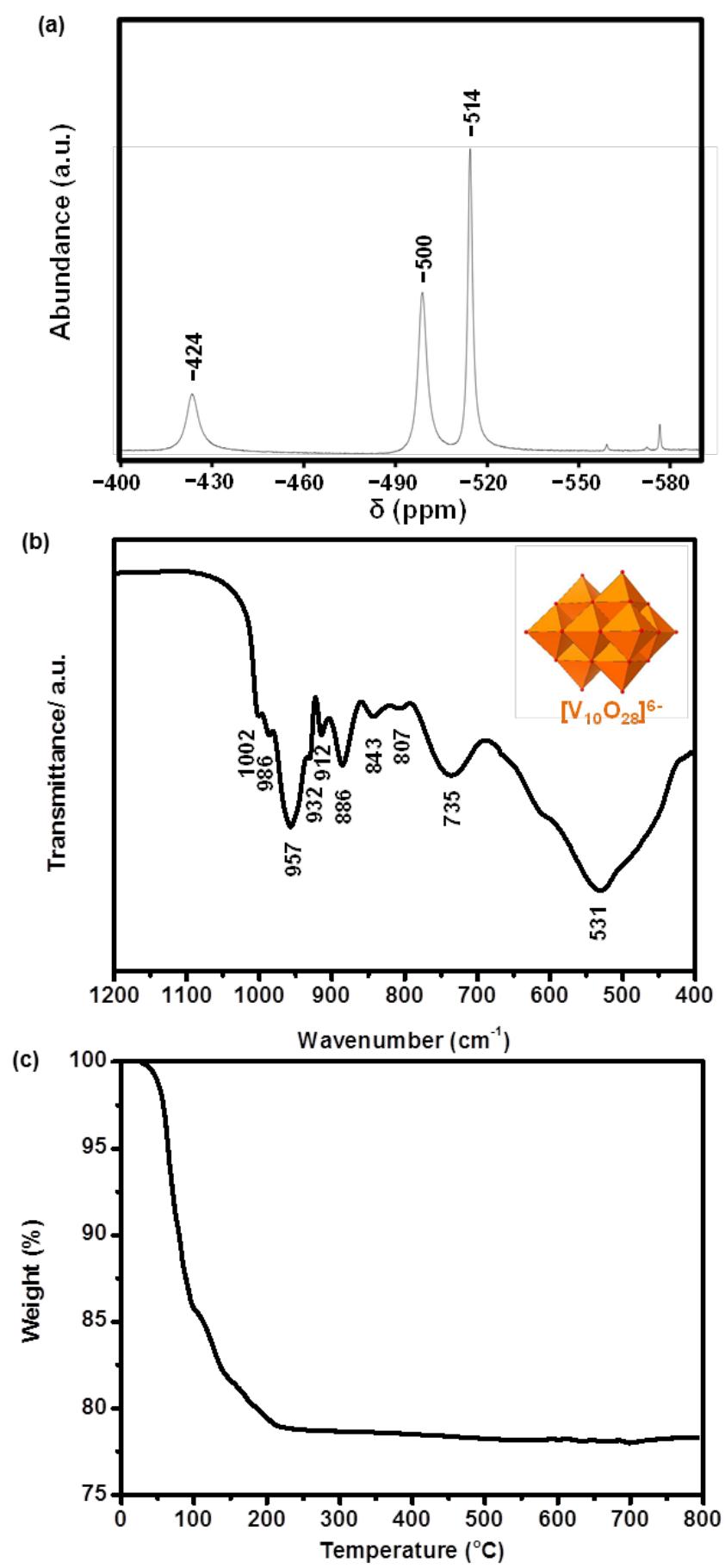

Figure 2 | Different characterization methods to identify the compound. (a) Shows that the ${ }^{51} \mathrm{~V}$ NMR spectrum of our POM similar to what would be expected from literature data. (b) Shows the absorption bands of the FTIR spectrum, and as an inset the polyhedral representation of $\left[\mathrm{V}_{10} \mathrm{O}_{28}\right]^{6-}$. (c) Illustrates the weight loss of the material during a TGA experiment with $\mathrm{Na}_{6}\left[\mathrm{~V}_{10} \mathrm{O}_{28}\right] \cdot 16 \mathrm{H}_{2} \mathrm{O}$. 
(a)

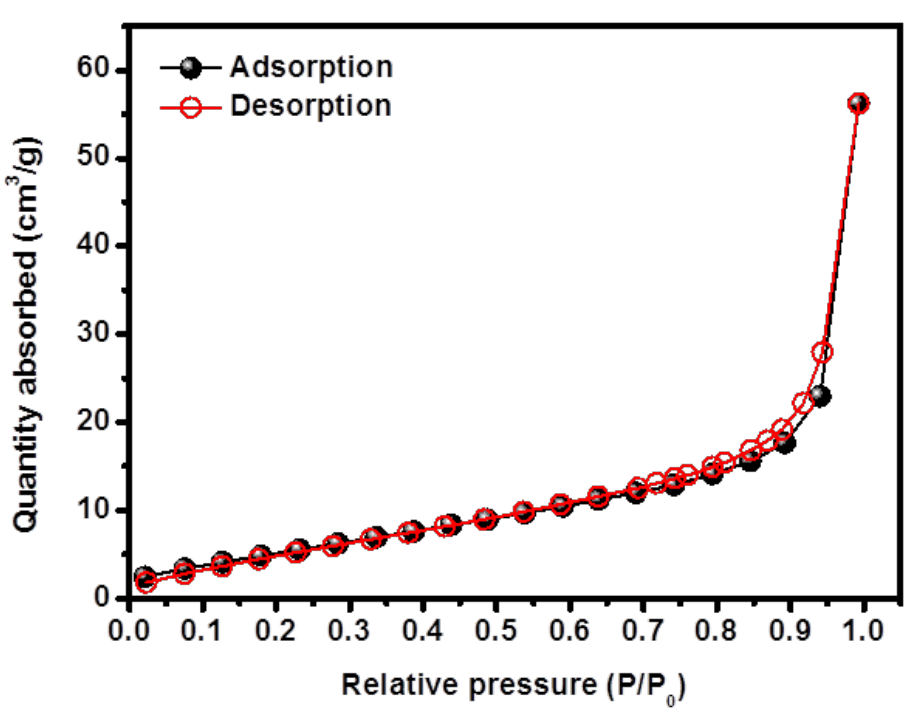

(b)

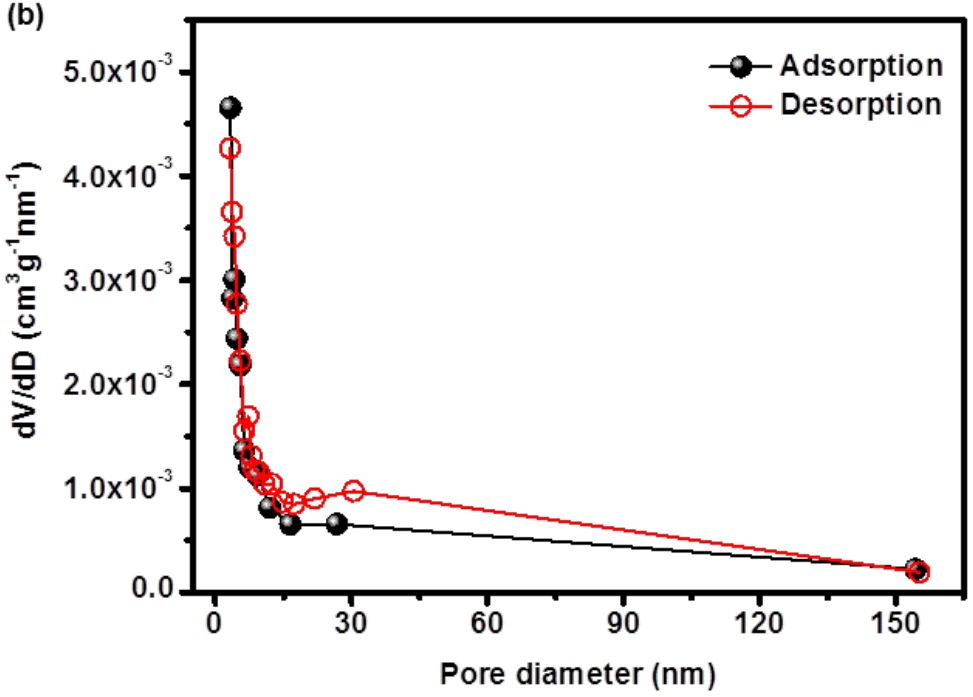

Figure 3 | Determination of the surface characteristics of the compound. (a)

Shows the graph resulting from BET measurements. (b) Illustrates the corresponding $\mathrm{BJH}$ pore size distribution for $\mathrm{Na}_{6}\left[\mathrm{~V}_{10} \mathrm{O}_{28}\right] \cdot 16 \mathrm{H}_{2} \mathrm{O}$. 

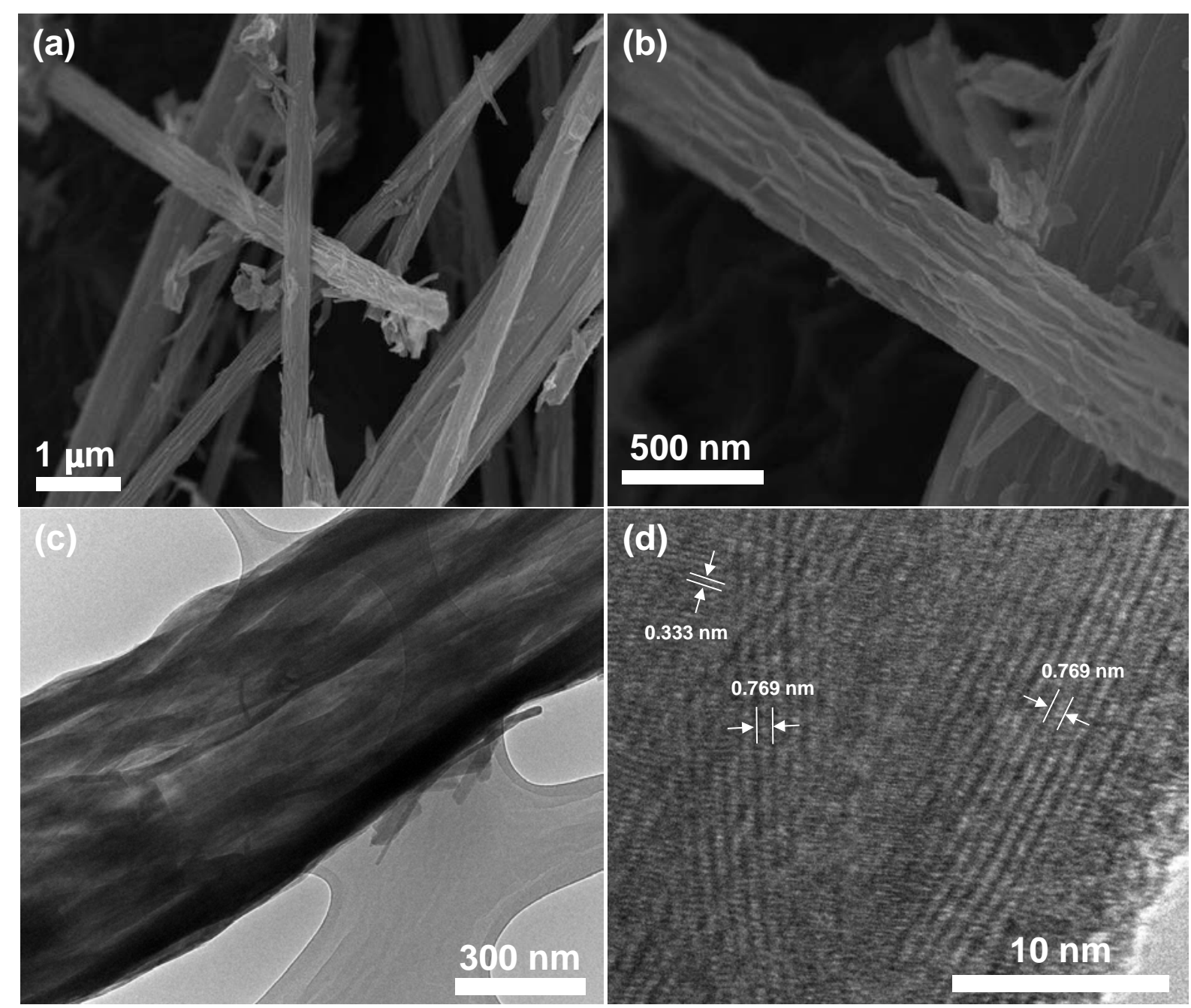

Figure 4 | Morphological analysis of the POM. (a), (b) \& (c) Illustrates the rod-like morphology of $\mathrm{Na}_{6}\left[\mathrm{~V}_{10} \mathrm{O}_{28}\right] \cdot 16 \mathrm{H}_{2} \mathrm{O}$ by $\operatorname{SEM}(\mathrm{a}, \mathrm{b})$ and bright-field TEM (c) measurements. (d) Shows the high-resolution TEM image of the POM. 
(a)

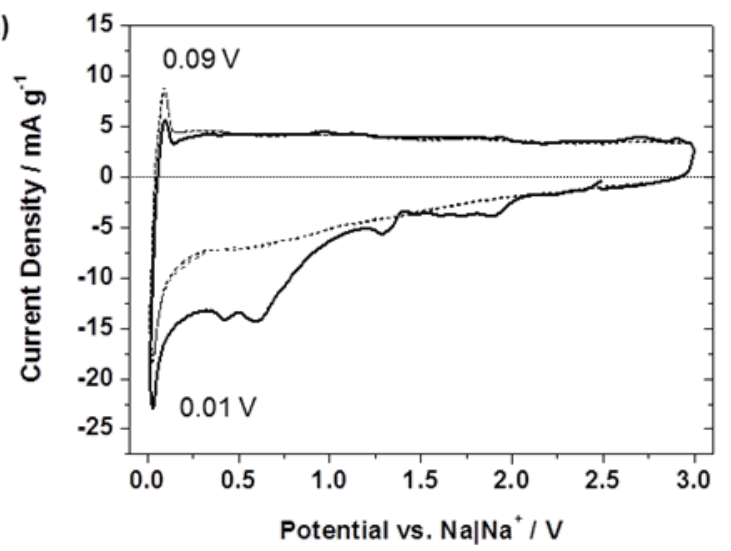

(b)

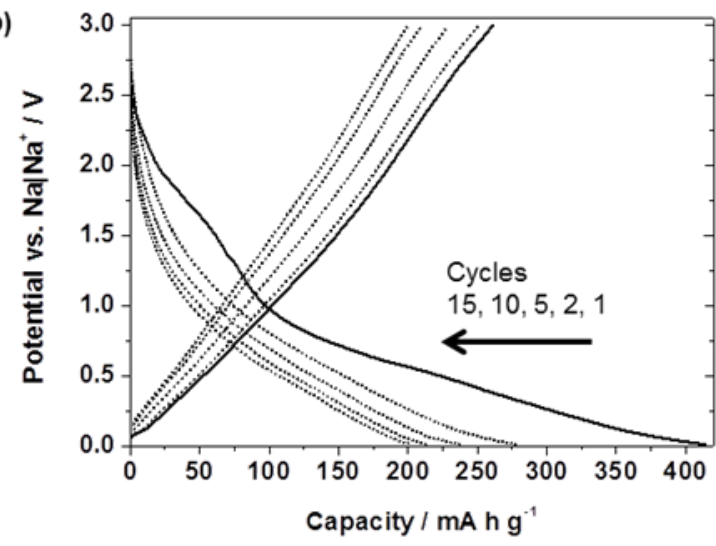

(c)

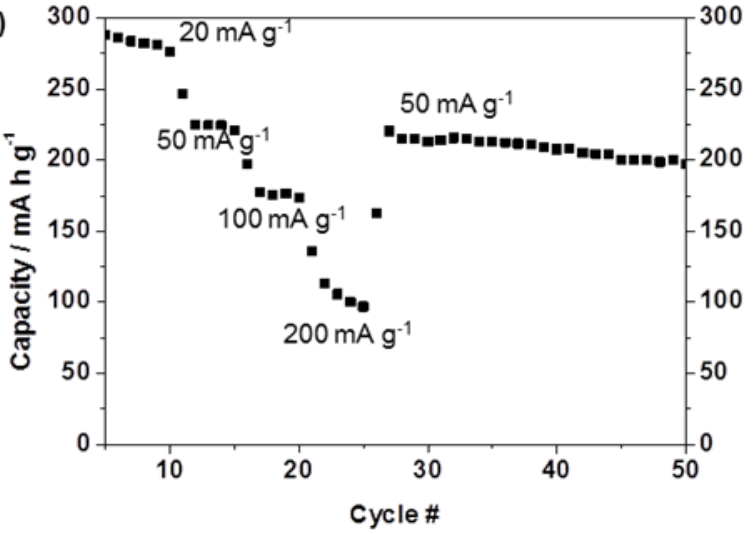

Figure 5 | Electrochemical behaviour and peformance of the POM electrode in a sodium cell. (a) Shows the cyclic voltammogram (cycles 1-5) of $\mathrm{Na}_{6}\left[\mathrm{~V}_{10} \mathrm{O}_{28}\right]$ in a half-cell set-up with $1 \mathrm{M} \mathrm{NaClO}_{4}$ in EC:PC (1:1\% weight) as electrolyte at a scan rate of $0.01 \mathrm{mV} \mathrm{s}^{-1}$ (b) Illustrates the galvanostatic charge / discharge profile in a half-cell set-up with $1 \mathrm{M} \mathrm{NaClO}_{4}$ in EC:PC (1:1\% weight) as electrolyte at $50 \mathrm{~mA} \mathrm{~g}^{-1}$. (c) Illustrates the rate capability and stability of $\mathrm{Na}_{6}\left[\mathrm{~V}_{10} \mathrm{O}_{28}\right]$ in a half-cell set-up with $1 \mathrm{M}$ $\mathrm{NaClO}_{4}$ in EC:PC (1:1\% weight) as electrolyte. 

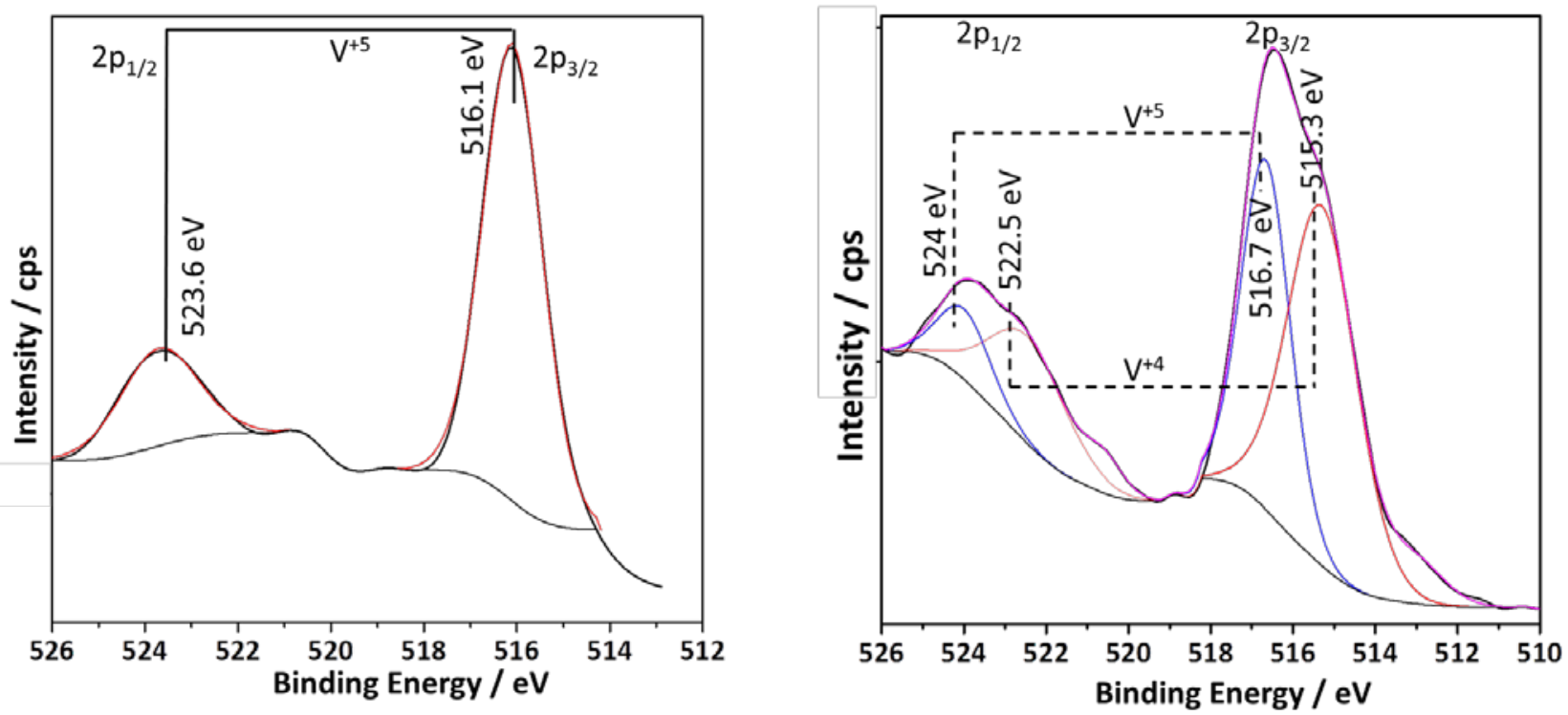

Figure 6 | Determination of the oxidation state of vanadium before and after cycling. Illustrates the oxidation state of vanadium in the POM by XPS measurements of (left) a pristine $\mathrm{Na}_{6}\left[\mathrm{~V}_{10} \mathrm{O}_{28}\right]$ electrode and (right) discharged $\mathrm{Na}_{6}\left[\mathrm{~V}_{10} \mathrm{O}_{28}\right]$ electrode. This shows that vanadium is reduced during $\mathrm{Na}^{+}$-insertion. 

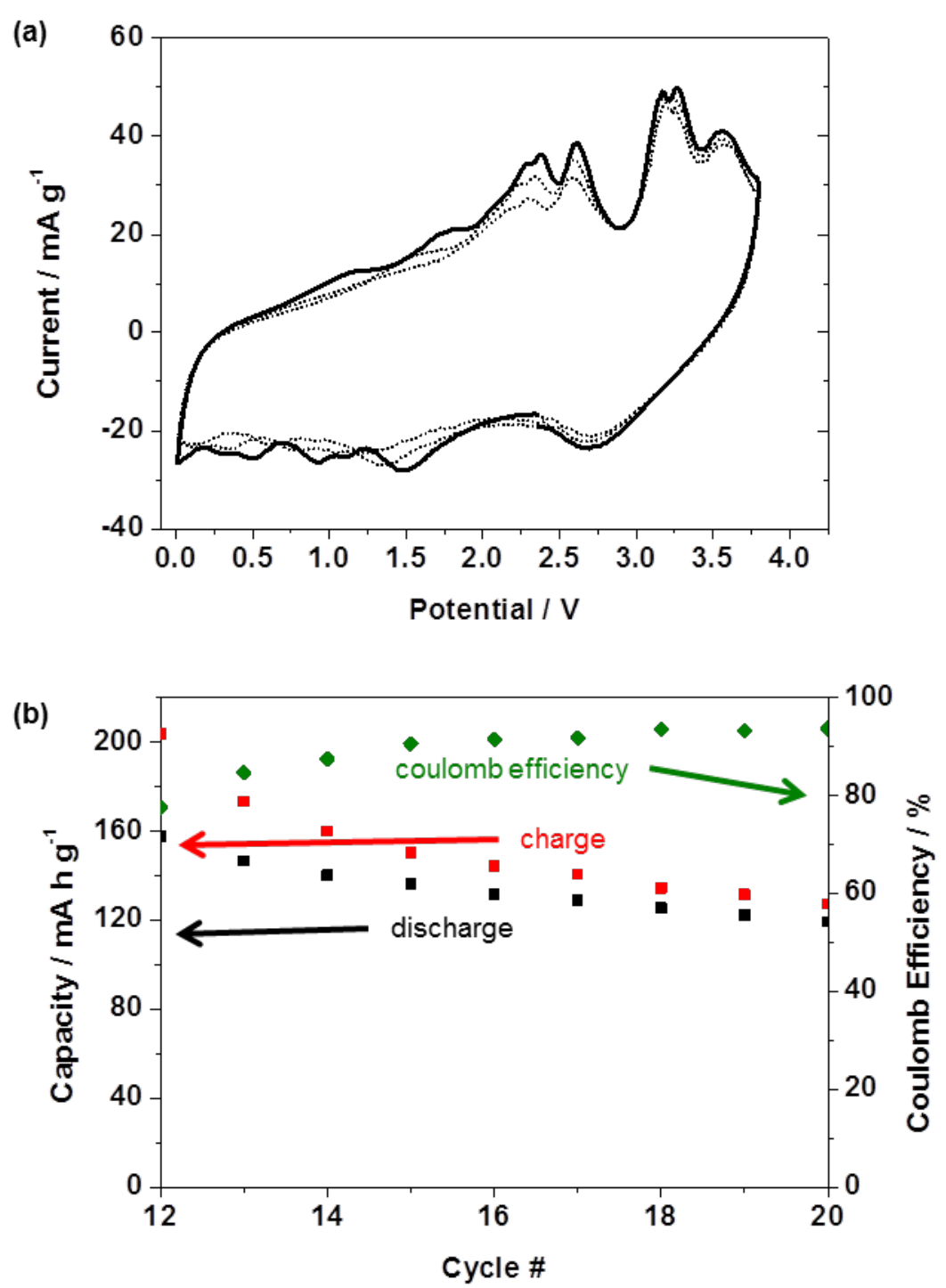

Figure 7 | Proof of concept for a POM -based full cell set-up. (a) Shows the cyclic voltrammogram of the full cell at $0.2 \mathrm{mV} / \mathrm{s}$. Anode: POM, Cathode: Spherical $\mathrm{Na}_{x} \mathrm{MnO}_{2+y}$ (not weight balanced). Cycles $7-9$ after cycling six times in a narrower voltage ranges. (b) Illustrates the full cell charge / discharge capacities with respect to the POM as well as the corresponding coulomb efficiencies. Anode: POM, Cathode: Spherical $\mathrm{Na}_{x} \mathrm{MnO}_{2+y}$ (not weight balanced). Potential range: $0-3.8 \mathrm{~V}$; previous cycles were cycled in narrower voltage ranges 


\section{List of references}

1. Palomares, V. et al. Na-ion batteries, recent advances and present challenges to become low cost energy storage systems. Energy Environ. Sci. 5, 58845901 (2012).

2. Palomares, V., Casas-Cabanas, M., Castillo-Martínez, E., Han, M. H. \& Rojo, $\mathrm{T}$. Update on Na-based battery materials. A growing research path. Energy Environ. Sci. 6, 2312-2337 (2013).

3. Pan, H., Hu, Y.-S. \& Chen, L. Room-temperature stationary sodium-ion batteries for large-scale electric energy storage. Energy Environ. Sci. 6, 23382360 (2013).

4. Komaba, S. et al. Electrochemical $\mathrm{Na}$ insertion and solid electrolyte interphase for hard-carbon electrodes and application to Na-Ion Batteries. Adv. Funct. Mater. 21, 3859-3867 (2011).

5. Komaba, S. et al. Fluorinated ethylene carbonate as electrolyte additive for rechargeable Na batteries. ACS Appl. Mater. Interfaces 3, 4165-4168 (2011).

6. Yabuuchi, N. et al. P2-type $\mathrm{Na}_{x}\left[\mathrm{Fe}_{1 / 2} \mathrm{Mn}_{1 / 2}\right] \mathrm{O}_{2}$ made from earth-abundant elements for rechargeable $\mathrm{Na}$ batteries. Nat. Mater. 11, 512-517 (2012).

7. Bucher, N. et al. Combustion-synthesized sodium manganese (cobalt) oxides as cathodes for sodium ion batteries. J. Solid State Electrochem. 17, 19231929 (2013).

8. Kim, D. et al. Layered $\mathrm{Na}\left[\mathrm{Ni}_{1 / 3} \mathrm{Fe}_{1 / 3} \mathrm{Mn}_{1 / 3}\right] \mathrm{O}_{2}$ cathodes for Na-ion battery application. Electrochem. commun. 18, 66-69 (2012).

9. D'Arienzo, M. et al. Layered $\mathrm{Na}_{0.71} \mathrm{CoO}_{2}$ : a powerful candidate for viable and high performance Na-batteries. Phys. Chem. Chem. Phys. 14, 5945-5952 (2012).

10. Guignard, M. et al. P2-Na $\mathrm{VO}_{2}$ system as electrodes for batteries and electroncorrelated materials. Nat. Mater. 11, 1-7 (2012).

11. Cao, Y. et al. Sodium ion insertion in hollow carbon nanowires for battery applications. Nano Lett. 12, 3783-3787 (2012).

12. Chevrier, V. L. \& Ceder, G. Challenges for Na-ion negative electrodes. J. Electrochem. Soc. 158, A1011-A1014 (2011).

13. Xiong, H., Slater, M. D., Balasubramanian, M., Johnson, C. S. \& Rajh, T. Amorphous $\mathrm{TiO}_{2}$ nanotube anode for rechargeable sodium ion batteries. $\mathrm{J}$. Phys. Chem. Lett. 2, 2560-2565 (2011). 
14. Wang, Y. et al. A zero-strain layered metal oxide as the negative electrode for long-life sodium-ion batteries. Nat. Commun. 4, 2365 (2013).

15. Senguttuvan, P., Rousse, G., Seznec, V., Tarascon, J.-M. \& Palacín, M. R. $\mathrm{Na}_{2} \mathrm{Ti}_{3} \mathrm{O}_{7}$ : Lowest voltage ever reported oxide insertion electrode for sodium ion batteries. Chem. Mater. 23, 4109-4111 (2011).

16. Rudola, A., Saravanan, K., Mason, C. W. \& Balaya, P. $\mathrm{Na}_{2} \mathrm{Ti}_{3} \mathrm{O}_{7}$ : an intercalation based anode for sodium-ion battery applications. J. Mater. Chem. A 1, 2653 (2013).

17. Sun, Y. et al. Direct atomic-scale confirmation of three-phase storage mechanism in $\mathrm{Li}_{4} \mathrm{Ti}_{5} \mathrm{O}_{12}$ anodes for room-temperature sodium-ion batteries. Nat. Commun. 4, 1870 (2013).

18. Aravindan, V., Ling, W. C., Hartung, S., Bucher, N. \& Madhavi, S. Carboncoated $\mathrm{LiTi}_{2}\left(\mathrm{PO}_{4}\right)_{3}$ : an ideal insertion host for lithium-ion and sodium-ion batteries. Chem. Asian J. 9, 878-82 (2014).

19. Oh, S.-M. et al. An advanced sodium-ion rechargeable battery based on a tincarbon anode and a layered oxide framework cathode. Phys. Chem. Chem. Phys. 15, 3827-33 (2013).

20. Wu, L. et al. SiC-Sb-C nanocomposites as high-capacity and cycling-stable anode for sodium-ion batteries. Electrochim. Acta 87, 41-45 (2013).

21. Xiao, L. et al. High capacity, reversible alloying reactions in SnSb/C nanocomposites for Na-ion battery applications. Chem. Commun. 48, 3321-3 (2012).

22. Qian, J. et al. High capacity Na-storage and superior cyclability of nanocomposite Sb/C anode for Na-ion batteries. Chem. Commun. 48, 70707072 (2012).

23. Stevens, D. A. \& Dahn, J. R. The mechanisms of lithium and sodium insertion in carbon materials. J. Electrochem. Soc. 148, A803 (2001).

24. Zhao, L. et al. Disodium terephthalate $\left(\mathrm{Na}_{2} \mathrm{C}_{8} \mathrm{H}_{4} \mathrm{O}_{4}\right)$ as high performance anode material for low-cost room-temperature sodium-ion battery. Adv. Energy Mater. 2, 962-965 (2012).

25. Park, Y. et al. Sodium terephthalate as an organic anode material for sodium ion batteries. Adv. Mater. 24, 3562-7 (2012).

26. Song, Y.-F. \& Tsunashima, R. Recent advances on polyoxometalate-based molecular and composite materials. Chem. Soc. Rev. 41, 7384-402 (2012).

27. Proust, A. et al. Functionalization and post-functionalization: a step towards polyoxometalate-based materials. Chem. Soc. Rev. 41, 7605-22 (2012). 
28. Lv, H. et al. Polyoxometalate water oxidation catalysts and the production of green fuel. Chem. Soc. Rev. 41, 7572-89 (2012).

29. U. Kortz. Special Issue: Polyoxometalates. Eur. J. Inorg. Chem. 2009, 50555276 (2009).

30. Pope, M. T. \& Kortz, U. Polyoxometalates. In Encyclopedia of Inorganic and Bioinorganic Chemistry. (John Wiley \& Sons, Ltd, 2011).

31. Sartorel, A., Bonchio, M., Campagna, S. \& Scandola, F. Tetrametallic molecular catalysts for photochemical water oxidation. Chem. Soc. Rev. 42, 2262-80 (2013).

32. Uematsu, S., Quan, Z., Suganuma, Y. \& Sonoyama, N. Reversible lithium charge e discharge property of bi-capped Keggin-type polyoxovanadates. J. Power Sources 217, 13-20 (2012).

33. Wang, H., Kawasaki, N., Yokoyama, T., Yoshikawa, H. \& Awaga, K. Molecular cluster batteries of nano-hybrid materials between Keggin POMs and SWNTs. Dalt. Trans. 41, 9863-9866 (2012).

34. Sonoyama, N., Suganuma, Y., Kume, T. \& Quan, Z. Lithium intercalation reaction into the Keggin type polyoxomolybdates. J. Power Sources 196, 6822-6827 (2011).

35. Xie, A., Ma, C., Wang, L. \& Chu, Y. $\mathrm{Li}_{6} \mathrm{~V}_{10} \mathrm{O}_{28}$, a novel cathode material for Liion battery. Electrochim. Acta 52, 2945-2949 (2007).

36. Ni, E., Uematsu, S., Quan, Z. \& Sonoyama, N. Improved electrochemical property of nanoparticle polyoxovanadate $\mathrm{K}_{7} \mathrm{NiV}_{13} \mathrm{O}_{38}$ as cathode material for lithium battery. J. Nanoparticle Res. 15, 1732 (2013).

37. Wang, H. et al. In operando X-ray absorption fine structure studies of polyoxometalate molecular cluster batteries: polyoxometalates as electron sponges. J. Am. Chem. Soc. 134, 4918-24 (2012).

38. Domaille, P. J. 1- and 2-dimensional tungsten-183 and vanadium-51 NMR characterization of isopolymetalates and heteropolymetalates. J. Am. Chem. Soc. 106, 7677-7687 (1984).

39. Ramos, S., Duarte, R. O., Moura, J. J. G. \& Aureliano, M. Decavanadate interactions with actin: cysteine oxidation and vanadyl formation. Dalt. Trans. 7985-94 (2009).

40. Frost, R. L., Erickson, K. L., Weier, M. L. \& Carmody, O. Raman and infrared spectroscopy of selected vanadates. Spectrochim. Acta. A. Mol. Biomol. Spectrosc. 61, 829-34 (2005). 
41. Mohammadi, M. R. \& Hakimi, M. Synthesis and low temperature crystal structure of disodium tetrapotasium decavanadate. E-Journal Chem. 9, 43-48 (2012).

42. Redlich, O. \& Kister, A. T. Algebraic representation of thermodynamic properties and the classification of solutions. Ind. Eng. Chem. 40, 345-348 (1948).

43. Karthikeyan, D. K., Sikha, G. \& White, R. E. Thermodynamic model development for lithium intercalation electrodes. J. Power Sources 185, 13981407 (2008).

44. Bucher, N. et. al. Layered $\mathrm{Na}_{x} \mathrm{MnO}_{2+z}$ in sodium ion batteries - influence of morphology on cycle performance. ACS Appl. Mater. Interfaces DOI:

10.1021/am406009t (2014) 


\section{Acknowledgements}

This work was financially supported by the Singapore National Research Foundation under its Campus for Research Excellence and Technological Enterprise (CREATE) programme.

\section{Author contributions}

M.S. conceived the idea of studying POMs in NIBs. S.H. and N.B. performed the electrochemical tests and wrote the manuscript. H.C. provided helpful input for the POM part of the manuscript. R. A.-O. and U.K. provided the POM as well as their expertise in this field. U.S. established the contact. H.E.H. helped with the electrochemistry part of the manuscript. S.S., P.B. and Y.Z. conducted and analysed the XPS measurements.

\section{Competing financial interests.}

The authors declare no competing financial interests. 


\section{Figure legends}

Figure 1 | Overview of different anode materials for sodium ion batteries. Illustrates the voltage profiles of different sodium ion battery anode materials. The circles represent potentials at which the respective materials have a plateau; for the other materials, the voltage profile is indicated. The capacities shown here represent approximate values after initial stabilization, i.e., after irreversible reactions in the first cycles.

Figure 2 | Different characterization methods to identify the compound. (a)

Shows that the ${ }^{51} \mathrm{~V}$ NMR spectrum of our POM is similar to what would be expected from literature data. (b) Shows the absorption bands of the FTIR spectrum, and as an inset the polyhedral representation of $\left[\mathrm{V}_{10} \mathrm{O}_{28}\right]^{6-}$. (c) Illustrates the weight loss of the material during a TGA experiment with $\mathrm{Na}_{6}\left[\mathrm{~V}_{10} \mathrm{O}_{28}\right] \cdot 16 \mathrm{H}_{2} \mathrm{O}$.

Figure 3 | Determination of the surface characteristics of the compound. (a) Shows the graph resulting from BET measurements. (b) Illustrates the corresponding $\mathrm{BJH}$ pore size distribution for $\mathrm{Na}_{6}\left[\mathrm{~V}_{10} \mathrm{O}_{28}\right] \cdot 16 \mathrm{H}_{2} \mathrm{O}$.

Figure 4 | Morphological analysis of the POM. (a), (b) \& (c) Illustrates the rod-like morphology of $\mathrm{Na}_{6}\left[\mathrm{~V}_{10} \mathrm{O}_{28}\right] \cdot 16 \mathrm{H}_{2} \mathrm{O}$ by $\operatorname{SEM}(\mathrm{a}, \mathrm{b})$ and bright-field TEM (c) measurements. (d) Shows the high-resolution TEM image of the POM.

Figure 5 | Electrochemical behaviour and peformance of the POM electrode in a sodium cell. (a) Shows the cyclic voltammogram (cycles 1-5) of $\mathrm{Na}_{6}\left[\mathrm{~V}_{10} \mathrm{O}_{28}\right]$ in a 
half-cell set-up with $1 \mathrm{M} \mathrm{NaClO}_{4}$ in $\mathrm{EC}: \mathrm{PC}(1: 1 \%$ weight) as electrolyte at a scan rate of $0.01 \mathrm{mV} \mathrm{s}^{-1}$ (b) Illustrates the galvanostatic charge / discharge profile in a half-cell set-up with $1 \mathrm{M} \mathrm{NaClO}_{4}$ in $\mathrm{EC}: P C(1: 1 \%$ weight $)$ as electrolyte at $50 \mathrm{~mA} \mathrm{~g}^{-1}$. (c) Illustrates the rate capability and stability of $\mathrm{Na}_{6}\left[\mathrm{~V}_{10} \mathrm{O}_{28}\right]$ in a half-cell set-up with $1 \mathrm{M}$ $\mathrm{NaClO}_{4}$ in EC:PC (1:1 \% weight) as electrolyte.

Figure 6 | Determination of the oxidation state of vanadium before and after cycling. Illustrates the oxidation state of vanadium in the POM by XPS measurements of (left) a pristine $\mathrm{Na}_{6}\left[\mathrm{~V}_{10} \mathrm{O}_{28}\right]$ electrode and (right) discharged $\mathrm{Na}_{6}\left[\mathrm{~V}_{10} \mathrm{O}_{28}\right]$ electrode. This shows that vanadium is reduced during $\mathrm{Na}^{+}$-insertion.

Figure 7 | Proof of concept for a POM -based full cell set-up. (a) Shows the cyclic voltrammogram of the full cell at $0.2 \mathrm{mV} / \mathrm{s}$. Anode: POM, Cathode: Spherical $\mathrm{Na}_{x} \mathrm{MnO}_{2+y}$ (not weight balanced). Cycles $7-9$ after cycling six times in a narrower voltage ranges. (b) Illustrates the full cell charge / discharge capacities with respect to the POM as well as the corresponding coulomb efficiencies. Anode: POM, Cathode: Spherical $\mathrm{Na}_{x} \mathrm{MnO}_{2+y}$ (not weight balanced). Potential range: $0-3.8 \mathrm{~V}$; previous cycles were cycled in narrower voltage ranges 